\title{
Skin AGEs and diabetic neuropathy
}

\author{
Stella Papachristou, Kalliopi Pafili and Nikolaos Papanas* (1)
}

\begin{abstract}
Advanced glycation end-products (AGEs) are heterogeneous molecules produced by the non-enzymatic glycation of proteins, lipids, or nucleic acids during hyperglycaemia. Accumulation of AGEs in the peripheral nerves has recently been proposed as an additional risk factor for the development of diabetic neuropathy (DN). The gold standard for measurement of tissue-bound AGEs is tissue biopsy. However, their assessment with the newer, fast and simple method of skin autofluorescence (SAF) has recently gained special interest by virtue of its non-invasive, highly reproducible nature and its acceptable correlation with the reference method of skin biopsy. Accumulation of tissue AGEs evaluated by SAF has been shown to independently correlate with DN. Importantly, increasing evidence underscores their potential value as early biomarkers of the latter. Further important associations include diabetic nephropathy, diabetic retinopathy and cardiovascular autonomic neuropathy. However, the value of the implementation of screening with skin AGEs for DN remains unclear. The aim of the present review is to critically summarise current evidence on the association between skin AGEs and diabetic microvascular complications, with a particular emphasis on diabetic neuropathy, and to note the most important limitations of existing knowledge. Longer follow-up studies are also highly anticipated to clarify its role and provide data on patient selection and cost-effectiveness.
\end{abstract}

Keywords: Advanced glycation end-products, Autofluorescence, Complications, Diabetes mellitus, Microvascular, Neuropathy

\section{Background}

Diabetic neuropathy (DN) is a very common complication of diabetes mellitus (DM) [1, 2]. It may have several variants, but distal symmetric sensorimotor neuropathy (diabetic peripheral neuropathy, DPN) is by far the commonest form, being the most frequent neurological complication of DM [1, 2]. Moreover, we now know that it may develop early in the course of diabetes, rather than being a predominantly late complication, as previously thought [1-3]. Indeed, DN may be detectable even during the first 12 months after the diagnosis of DM, or occasionally even in prediabetes [1-3]. Despite all that, DN is still suboptimally diagnosed [1-4]. Granted that it increases morbidity and mortality, as well as being a

\footnotetext{
* Correspondence: papanasnikos@yahoo.gr

Diabetes Centre-Diabetic Foot Clinic, Second Department of Internal

Medicine, Democritus University of Thrace, University Hospital of

Alexandroupolis, G. Kondyli 22c, 68100 Alexandroupolis, Greece
}

cardinal factor in the aetiopathogenesis of the diabetic foot [1-4], improved diagnosis is a medical need.

In recent years, metabolic byproducts called advanced glycation end-products (AGEs) have attracted scientific interest [5-7]. Indeed, many studies have strongly linked them with the development and progression of DM and its complications $[5,6]$. Thus, their non-invasive measurement, for instance in the skin, has been proposed in the overall diagnostic work-up of DM [5]. To this purpose, the autofluorescent properties of AGEs are employed, without discomfort for the patient [5]. Thus, an increasing number of studies has tried to establish skin AGEs as predictors of microvascular diabetic complications. Nonetheless, to the best of our knowledge, a systematic estimation of this relationship has not been performed during the last decade, and associations remain rather controversial [8]. 
In this context, the purpose of the present brief narrative review is to critically summarise current knowledge on the relationship between skin AGEs and diabetic neuropathy with a brief reference to the other microvascular complications of DM. Indeed, some recent publications during the last 3 years have provided interesting additional evidence in this field, allowing us to reexamine the subject.

\section{Advanced glycation end-products}

AGEs represent a rather heterogeneous class of molecules produced by the non-enzymatic glycation of proteins, lipids, or nucleic acids during a hyperglycaemic state $[5,6]$. The reaction resulting in the formation of AGEs is known as the "Maillard reaction" [5]. AGEs then undergo extracellular proteolysis followed up by intracellular uptake by tissue macrophages, and are finally excreted by the kidneys $[5,6]$.

AGEs can accumulate with age. However, their accumulation is exacerbated by some pathologic conditions such as DM, cardiovascular disease, Alzheimer's disease etc. [5-7]. Food products which undergo heatprocessing are also a significant source of AGEs: the latter are partially absorbed during ingestion [6, 7]. These food products also produce Maillard reaction products, including AGEs [6,7]. Reduction in cooking temperature has been shown to decrease AGE levels, as measured by calculating levels of carboxymethyl-lysine (CML) [6]. Moreover, $\mathrm{pH}$ levels play a major role in the development of AGEs and pretreating food products with acidic substances such as vinegar and lemon have been shown to reduce AGEs [6, 7].

AGEs can be absorbed by simple diffusion if found in their free form. However, the absorption of their protein-bound form is less successful [7]. As confirmed by measurement of faecal AGEs, individuals who have had pentosidine in its free form (in coffee) absorb more AGEs when compared with those ingesting it in its protein-bound form (in bread) [7].

Interestingly, coffee consumption has also been shown to have a significant and dose-dependent correlation with sAF levels in subjects without DM [9]. However, in individuals with type $2 \mathrm{DM}$ (T2DM), there was a nonsignificant trend [9]. Other than dietary sources, smoking has also been found to be a major source of exogenous AGEs [10]. In individuals who were past or current smokers, sAF levels were higher compared with never smokers, and this did not depend on the presence or not of DM [10]. As was the case with coffee consumption, sAF levels were closely associated with number of packs/ years, which strongly suggested a dose-dependent effect [10]. These results have been confirmed in another study, in which it was additionally shown that smoking cessation results in a gradual decrease of sAF levels [11].

\section{DN}

Traditionally, DN is classified into diffuse and focal [1, 4]. It may affect the somatic or the autonomic part of the peripheral nervous system $[1,4]$. In the latter case, it is called diabetic autonomic neuropathy (DAN), and its most important manifestations are seen in the gastroinstestinal and the cardiovascular system $[1,4,12]$. Overall, the commonest form of DN is, as aforesaid, DPN [1, 4].

The main risk factors of DN include DM duration, marked hyperglycaemia, dyslipidaemia, hypertension, smoking and age [13]. Its pathogenesis is hugely complex and can be seen as an incompletely understood conundrum of hyperglycaemia, insulin resistance, chronic inflammation, oxidative stress, dyslipidaemia, endothelial dysfunction and (in the case of type $1 \mathrm{DM}$ ) inadequacy of insulin $[1,4]$. Nowadays, an additional causative factor is considered to be the accumulation of AGEs in the peripheral nerves, increasing reactive oxygen species (ROS) and, finally, promoting neural inflammation and impairing axonal transport (Fig. 1). Such accumulation has been associated with lower limb sensory loss [14].

DPN typically presents as chronic insidious progressive symmetrical sensory loss in the distal parts of the lower extremities (so called "stocking and glove distribution") $[1,3,4]$. This relates to temperature, pain, light touch and vibration perception $[1,4]$. In more advanced cases, motor deficits (muscle weakness, attenuation of Achilles reflexes) manifest as well. Moreover, impaired sweat gland innervation renders the skin dry and fragile $[1,4]$. Most patients are asymptomatic, while the combination of these deficits places the feet at increased risk of foot ulceration through unrecognised trauma $[1,3,4]$. Occasionally, patients may complain of numbness pain or discomfort, which may exhibit nocturnal exacerbation $[1,4]$.

The diagnosis of $\mathrm{DN}$ rests on clinical examination, depending on the system affected $[1,4,15]$. For example, cardiovascular reflex tests are used to diagnose cardiovascular autonomic neuropathy $[1,16]$. For DPN, simple bedside clinical examination assessing sensory and motor nerve fibres is used [1, 15]. More sophisticated methods are mainly used for difficult cases, differential diagnosis or research purposes $[1,15]$. To enable wider DPN screening, some simple new diagnostic tools have been developed as well: the most important of these are automated sural nerve conduction study $[17,18]$ and the indicator test Neuropad assessing skin dryness by means of a very simple colour change [18].

The therapeutic principles of DN may be summarised as follows: optimisation of glycaemic control, treatment of other vascular risk factors (dyslipidaemia, hypertension, smoking), pathogenesis-oriented treatment, 


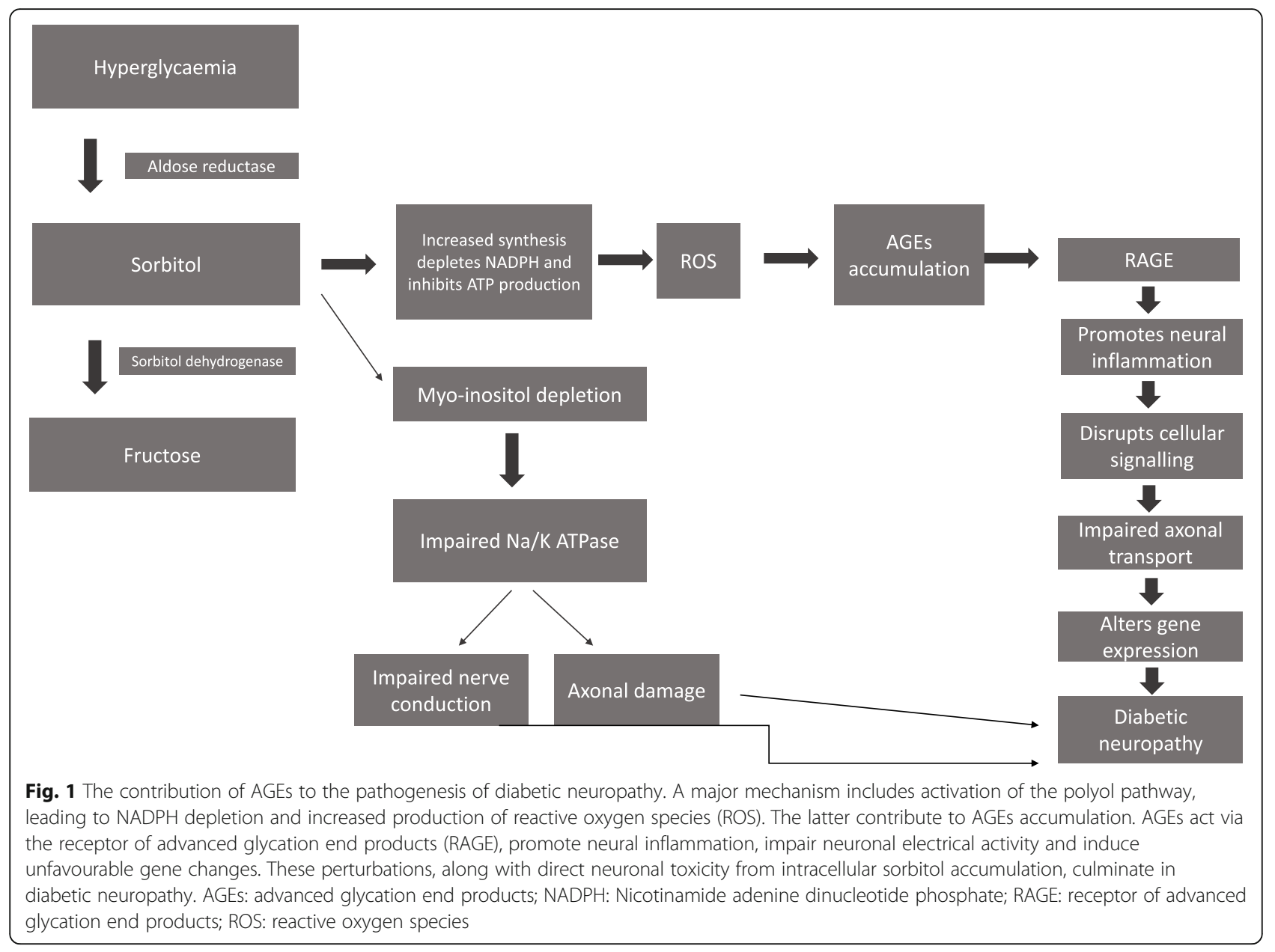

analgesia as required and avoidance of complications (such as foot ulceration) [1, 4, 19]. There has been considerable progress in pain relief $[1,4,19]$. Conversely, pathogenesis-oriented treatment is still suboptimal and only alpha-lipoic acid has shown efficacy $[4,19]$.

\section{Measurement of skin AGEs}

AGEs are currently measured by means of Enzymelinked immunosorbent assay (ELISA) using monoclonal or polyclonal antibodies, high performance liquid chromatography (HPLC) and mass spectrography $[5,9]$. However, the gold standard for measurement of tissuebound AGEs is undoubtedly tissue biopsy. This method is highly accurate and provides great insight into disease process, but it is invasive and takes a much longer period compared to the newer methods [5, 9].

Skin autofluorescence is measured using an autofluorescence reader (e.g. AGE reader mu connect; Diagnoptics, NL) (Fig. 2), which illuminates a small portion of the skin (approximately $4 \mathrm{~cm}^{2}$ ) on the volar side of the examinees' forearm $[5,20]$. The device produces light on the selected area with an excitation light source of $\sim 370$ $\mathrm{nm}$. The emission light and reflected excitation light emanating from the skin is then measured using a glass fibre in the $300-600 \mathrm{~nm}$ range [20]. These values are then computerised and through a series of calculations produce values in arbitrary units (AU). Meerwalt et al. [21] have shown that measurements by the AGE reader exhibited adequate correlations with readings from skin biopsies for specific AGEs, such as pentosidine, CML and carboxyethyl lysine (CEL) [5].

\section{Skin AGEs and diabetic microvascular complications}

In recent years, skin AGEs have been utilised more frequently for diagnostic purposes as they offer a noninvasive, and inexpensive diagnostic tool with a high degree of reproducibility. Increased skin AGEs has been thoroughly studied in the context of microvascular complications of diabetes mellitus (Table 1) [5, 22-33].

In the case of retinopathy, apoptosis of retinal capillary pericytes and endothelial cells (a major contributor to the pathogenesis of this complication) has been linked with AGEs [5]. In alloxan-induced diabetes, AGEspecific modifications of the basement membrane proteins of retinal capillaries were observed [32]. Another 


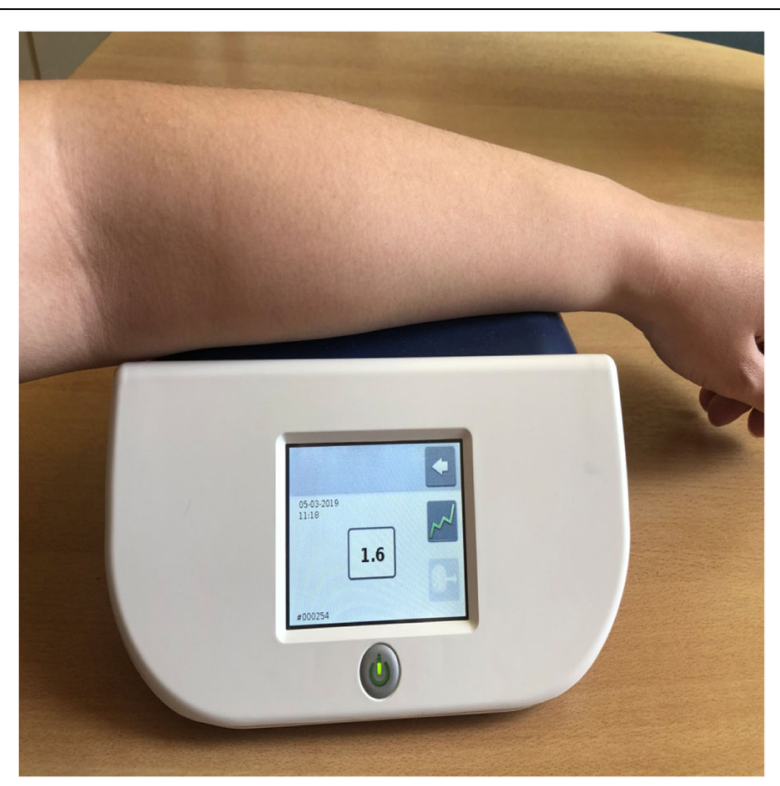

Fig. 2 Skin autofluorescence, as measured by the autofluorescence reader AGE reader mu connect (Diagnoptics, NL). Local creams should not have been applied for $12 \mathrm{~h}$. The examinee places the forearm of his/her dominant upper limb on the silicone armrest of the device. In this armrest, there is a small examination window for selection of a skin area. The elbow should be aligned with the edge of the armrest and no movements should be made during measurement. The examiner switches on the device using the power button. Activation is performed through the menu on the touch screen. AGEs result is shown on the screen. Approximate measurement duration is $30 \mathrm{~s}$. Interpretation of results may be facilitated by available age- and sex-adjusted normative data

group reported that increased AGEs are linked with vascular endothelial growth factor (VEGF) overproduction (another major pathogenetic mechanism) [32]. Nevertheless, previous evidence is rather controversial, with a number of studies reporting lack of association with skin AGEs [23, 30, 34], others reporting a clear independent correlation with retinopathy $[24,25,28]$ and disease severity [29], whereas, interestingly, macular oedema seems to develop independently of any increase in the levels of skin AGEs (Table 1) [26, 29].

In diabetic nephropathy, AGEs can affect extracellular matrix (ECM) protein in the glomerular mesangium and tubulointerstitium $[5,35]$. This is mediated by alterations in protein structure and composition, as well as increase in matrix formation $[5,14]$. The latter is attributable to the fact that proteins become more resistant to enzymatic digestion. A potential role of AGEs in the development of diabetic nephropathy by influencing the renin-angiotensin system has also been suggested. This interaction has been demonstrated in vitro by the reversal of AGE-induced collagen formation with captopril [31]. Nonetheless, previous studies do not unanimously support the correlation between nephropathy and skin AGEs (Table 1) [22-25, 27, 30, 31].

\section{Skin AGEs and DN}

Accumulation of tissue AGEs evaluated by sAF was independently associated with DPN (diagnosed by the presence of at least two of the following: sensory symptoms, bilaterally decreased or absent ankle reflexes, and decreased vibration perception in bilateral medial malleoli) among 193 T2DM persons following correction for known risk factors of microvascular complications [36]. Wan et al. [37] have further demonstrated that increased sAF levels are directly correlated with impairments in nerve conduction velocity and nerve conduction amplitude. In T2DM individuals with sAF levels above 2.2 $A U$, there was a significant decrease in sensory nerve conduction velocity and compound action potential of the sural and superficial peroneal neve [37]. Importantly, sAF greater than 2.7 AU exhibited a further significant negative correlation with deterioration of the aforementioned parameters, as compared with sAF levels $\leq 2.2$ AU and sAF 2.2-2.7 AU [37]. Additionally, in a multicentre study including 497 T1DM and T2DM humans, sAF levels significantly increased with the clinical severity of DPN, as graded by the Toronto Clinical Neuropathy Score [38].

A further prospective 4-year study confirmed the value of sAF to predict the development of DPN in a middleaged T1DM cohort with long-standing T1DM [31]. Even after adjustment for multiple confounding factors (age, sex, height, body mass index, tobacco, glycated haemoglobin, diabetes duration, estimated glomerular filtration rate and albumin excretion rate), each standard deviation change in baseline SAF was correlated with an almost 3-fold increased risk of developing signs of DPN [31]. The latter were defined by the occurrence of neuropathic pain and/or feet sensory loss, foot ulceration or neuropathic osteoarthropathy 4 years later [31]. As regards neuropathic symptoms, the potential contribution of AGEs to the development of painful DPN, may be partly explained on the basis of previously published evidence suggesting that AGEs (mainly methylglyoxal) may cause diabetic neuropathic hyperalgesia by increasing the electrical excitability and facilitating firing of nociceptive sensory neurons [39].

Impressively, there is also evidence of increased sAF levels before the onset of DPN symptoms. This further reinforces the notion that altered SAF could precede the progression of DPN. Indeed, a study has shown that sAF was correlated negatively with nerve conduction velocity and nerve conduction amplitude of the median, peroneal and sural nerve in humans with T1DM or T2DM even without the clinical manifestations of DPN [38]. Here DPN was defined using the Dutch Diabetic Neuropathy Symptoms scale, the Dutch Diabetic Neuropathy Examination scale, and quantitative sensory function testing with Semmes-Weinstein monofilaments (SWMF) [34]. 
Table 1 Human studies investigating the association between skin AGEs and microvascular complications other that diabetic neuropathy

\begin{tabular}{|c|c|c|c|}
\hline $\begin{array}{l}\text { First Author } \\
\text { (year) }\end{array}$ & $\begin{array}{l}\text { Participants and } \\
\text { diabetes type }\end{array}$ & Aggregate clinical outcome & Main findings \\
\hline \multicolumn{4}{|l|}{ Retinopathy } \\
\hline $\begin{array}{l}\text { Gerrits } \\
\text { (2008) [22] }\end{array}$ & 973 T2DM & Retinal photography & $\begin{array}{l}\text { Multivariate analysis (adjustment for sex, diabetes } \\
\text { duration, } \mathrm{HbA} \mathrm{A}_{1 \mathrm{c}} \text { current smoking, systolic blood } \\
\text { pressure, } \mathrm{HDL} \text { cholesterol, LDL cholesterol, triglycerides, } \\
\text { BMI): no association }\end{array}$ \\
\hline $\begin{array}{l}\text { Chabroux } \\
\text { (2010) [23] }\end{array}$ & 133 T1DM & Retinal photography & $\begin{array}{l}\text { Multivariate analysis (adjustment for age, diabetes } \\
\text { duration, } \mathrm{HbA}_{1 c} \text { smoking, retinopathy, nephropathy } \\
\text { and neuropathy): no association }\end{array}$ \\
\hline $\begin{array}{l}\text { Sugisawa } \\
(2013)[24]\end{array}$ & $\begin{array}{l}210 \mathrm{~T} 1 \mathrm{DM} / 110 \\
\text { controls }\end{array}$ & Retinal or fundus photography & $\begin{array}{l}\text { Multivariate analysis (adjustment for age at registration, } \\
\text { age at onset of diabetes, duration of diabetes, sex, BMI, } \\
\text { and SAF): positive association with retinopathy; positive } \\
\text { association with retinopathy severity }\end{array}$ \\
\hline $\begin{array}{l}\text { Yoshioka } \\
\text { (2018) [25] }\end{array}$ & $\begin{array}{l}162 \mathrm{~T} 2 \mathrm{DM} / 42 \\
\text { controls }\end{array}$ & $\begin{array}{l}\text { Diagnosed by independent ophthalmologists } \\
\text { according to a position statement by the American } \\
\text { Diabetes Association (no further information in the } \\
\text { text) }\end{array}$ & $\begin{array}{l}\text { Multivariate analysis (adjustment for age, diabetes } \\
\text { duration, } \mathrm{HbA}_{1 c} \text {, serum pentosidine concentration and } \\
\text { eGFR): positive association; positive association with } \\
\text { retinopathy severity }\end{array}$ \\
\hline $\begin{array}{l}\text { Bentata } \\
(2017)[26]\end{array}$ & $\begin{array}{l}444 \text { T2DM }(17 \% \\
\text { with chronic } \\
\text { renal } \\
\text { insufficiency) }\end{array}$ & $\begin{array}{l}\text { Fundus examination or retinography or (if required) } \\
\text { optical coherence tomography }\end{array}$ & $\begin{array}{l}\text { Multivariate analysis (adjustment for age, duration of } \\
\text { diabetes, hypertension, insulin, } \mathrm{HbA} \mathrm{A}_{1 c} \text { and } \mathrm{eGFR} \text { ): no } \\
\text { association of sAF and retinopathy among subjects } \\
\text { with T2DM and renal insufficiency; positive association } \\
\text { among subjects with T2DM and eGFR } 260 \mathrm{ml} / \mathrm{min} / \mathrm{m}^{2}\end{array}$ \\
\hline $\begin{array}{l}\text { Tanaka } \\
\text { (2012) [27] }\end{array}$ & $130 \mathrm{~T} 2 \mathrm{DM}$ & Retinal photography & $\begin{array}{l}\text { Positive association with proliferative diabetic } \\
\text { retinopathy but not with simple diabetic retinopathy }\end{array}$ \\
\hline $\begin{array}{l}\text { Yasuda } \\
\text { (2015) [28] }\end{array}$ & $\begin{array}{l}67 \mathrm{~T} 2 \mathrm{DM} / 67 \\
\text { controls }\end{array}$ & Fundus photography & Association with presence and severity of retinopathy \\
\hline $\begin{array}{l}\text { Hirano } \\
\text { (2014) [29] }\end{array}$ & $\begin{array}{l}138 \mathrm{~T} 2 \mathrm{DM} / 111 \\
\text { controls }\end{array}$ & $\begin{array}{l}\text { Ophthalmoscopy and contact lens slit lamp } \\
\text { biomicroscopy }\end{array}$ & $\begin{array}{l}\text { Multivariate analysis (adjustment for sex, age, } \mathrm{HbA}_{1 c} \\
\text { self-stated duration of diabetes, systolic and diastolic } \\
\text { blood pressure, history of smoking, diabetic nephropa- } \\
\text { thy, and diabetic neuropathy): association with retinop- } \\
\text { athy severity; no association with diabetic macular } \\
\text { oedema }\end{array}$ \\
\hline
\end{tabular}

Noordzij 563 T2DM Retinal photography or fundoscopy

\section{Nephropathy}

Gerrits

(2008) [22]

Chabroux

(2010) [23] controls

133 T1DM
973 T2DM

\section{Detection of (micro)albuminuria}

First method: chronic kidney disease stages 1-5 defined by National Kidney Foundation practice guidelines;

second method: 1) normoalbuminuria (ACR $<30 \mathrm{mg} / \mathrm{g}$ Cr); 2) incipient nephropathy (ACR $\geq 30$ but $<300 \mathrm{mg} / \mathrm{g}$

$(\mathrm{Cr}) ; 3$ ) overt nephropathy ( $A C R \geq 300 \mathrm{mg} / \mathrm{g} \mathrm{Cr}$ ); 4) chronic renal failure (serum $\mathrm{Cr}>2.0 \mathrm{mg} / \mathrm{dL}$ ); and 5) renal failure on dialysis

Classified as: (1) pre-nephropathy (stage 1) $(\mathrm{ACR}<30$ $\mathrm{mg} / \mathrm{g} \mathrm{Cr}) ;(2)$ incipient nephropathy (stage 2) $(30 \leq$ ACR $<300 \mathrm{mg} / \mathrm{g} \mathrm{Cr}$ ); (3) overt nephropathy (stage 3) (ACR $\geq 300 \mathrm{mg} / \mathrm{g} \mathrm{Cr}$ ); (4) kidney failure (stage 4) eGFR $<30 \mathrm{ml} / \mathrm{min} / 1.73^{2}$; and (5) dialysis therapy (stage 5)

Chronic kidney disease (eGFR $<90 \mathrm{ml} / \mathrm{min}$ ) and/or albuminuria
Multiple linear regression: no association

Multivariate analysis (adjustment for sex, diabetes duration, $\mathrm{HbA}_{1 c}$ current smoking, systolic blood pressure, HDL cholesterol, LDL cholesterol, triglycerides, BMI): positive association

Multivariate analysis (adjustment for age, diabetes duration, $\mathrm{HbA}_{1 c}$, smoking, retinopathy, nephropathy and neuropathy): positive association

Multivariate analysis (adjustment for age at registration, age at onset of diabetes, duration of diabetes, sex, BMl, and SAF): positive association with nephropathy; positive association with severity of nephropathy

Multivariate analysis (adjustment for age, diabetes duration, $\mathrm{HbA}_{1 \mathrm{c}}$, serum pentosidine concentration and eGFR): no association; positive association with incipient nephropathy (stage 2) but not with overt nephropathy (stage 3)

Increase of SAF (by at least 10\%): linked with deterioration of microalbuminuria and of eGFR 
Table 1 Human studies investigating the association between skin AGEs and microvascular complications other that diabetic neuropathy (Continued)

\begin{tabular}{llll}
\hline $\begin{array}{l}\text { First Author } \\
\text { (year) }\end{array}$ & $\begin{array}{l}\text { Participants and } \\
\text { diabetes type }\end{array}$ & Aggregate clinical outcome & Main findings \\
\hline $\begin{array}{l}\text { Tanaka } \\
\text { (2012) [27] }\end{array}$ & 130 T2DM & Positive dipstick results for proteinuria $(\geq 1+)$ & Positive association with proteinuria $\geq 3.5 \mathrm{~g} / \mathrm{gCr}$ \\
$\begin{array}{l}\text { Noordzij } \\
\text { (2012) }[30]\end{array}$ & 563 T2DM & ACR $>3.5$ in women and $>2.5$ in men & Multivariate analysis: no association
\end{tabular}

$A C R$ Albumin-to-creatinine ratio, $B M I$ body mass index, $C r$ creatinine, eGFR estimated glomerular filtration rate, $H b A_{1 c}$ glycated haemoglobin, $H D L$ high density lipoprotein, $L D L$ low density lipoprotein, SAF skin autofluorescence, T1DM type 1 diabetes mellitus, T2DM type 2 diabetes mellitus

These results were replicated in a longitudinal study involving 881 well-controlled T2DM participants [22]. After a mean follow-up of approximately 3 years, the relationship between SAF and development of DPN (diagnosed by SWMF) remained significant after adjustment for T2DM duration [22].

Furthermore, high SAF levels have been observed in individuals with diabetic foot ulcers [40, 41]. However, the highest SAF quartile has been independently associated with increased VPT levels even before reaching a VPT indicating high risk of foot ulceration [40, 41]. In the same context, an inverse relationship between high sAF levels and lower electrochemical skin conductance has been demonstrated, even in the normal range of sudomotor function, thereby providing evidence that increased sAF levels may even precede small-fibre sudomotor dysfunction [31].

Finally, Orchard et al. [35] have shown a strong association between sAF and CAN, as assessed by sinus arrhythmia. This extends the importance of AGEs from DPN to CAN as well, although the literature is rather controversial (Table 2) [34-36, 42].

\section{Clinical implications}

Measurement of skin AGEs has become very easy and reproducible with modern technology. Indeed, previous methods of AGEs measurement, although accurate and useful for diagnostic purposes, were invasive, expensive and therefore unsuitable for widespread use. The availability of skin AGEs has enabled their consideration as markers of microvascular diabetic complications. Indeed, should increased skin AGEs be demonstrated unequivocally to herald the development and/or deterioration of these complications, they might prove useful in their early detection. Thus, they might be expected to contribute to closer follow-up of high-risk individuals, early treatment initiation and avoidance of further deterioration, perhaps also improved quality of life [43].

So far, AGEs have been shown to correlate with DPN, CAN, diabetic retinopathy and nephropathy. In DN, they are being increasingly appreciated as promising early markers of this complication. They appear to become increased before the impairment of nerve conduction parameters, onset of symptoms or increase in vibration perception threshold. This evidence notwithstanding, important limitations of the literature pertain to differences in the populations studied and various diagnostic criteria of DPN (Table 3).

The question, then, arises as to whom, when and how often we shall screen. Ideally humans with DM should be offered early measurement of skin AGEs as screening of DN [44]. However, despite the easy-to-use devices, it is not possible to screen all DM individuals, and so, for the time being, it may be enough to increase AGEs measurements. Moreover, one might argue that while skin AGEs are correlated with incipient nerve fibre impairment, the improvement in $\mathrm{DN}$ as a result of AGEs screening remains a speculation and has not yet been demonstrated. Indeed, we would like to know more on this issue, including the cost-effectiveness of widespread screening [45]. Finally, longer follow-up of patients with early increases in skin AGEs is highly welcome.

Table 2 Human studies investigating the association between skin AGEs and cardiovascular autonomic neuropathy

\begin{tabular}{|c|c|c|c|}
\hline $\begin{array}{l}\text { First Author } \\
\text { (year) }\end{array}$ & $\begin{array}{l}\text { Participants and } \\
\text { diabetes type }\end{array}$ & Method of assessment of CAN & Main findings \\
\hline $\begin{array}{l}\text { Osawa (2018) } \\
{[36]}\end{array}$ & $\begin{array}{l}193 \mathrm{~T} 2 \mathrm{DM} / 24 \\
\text { controls }\end{array}$ & Heart rate variability & $\begin{array}{l}\text { Multivariate analysis (adjustment for age, sex, } \mathrm{HbA}_{1 c}, \mathrm{~T} 2 \mathrm{DM} \text { duration, } \mathrm{BN} \\
\text { hypertension, dyslipidaemia and smoking history): positive association }\end{array}$ \\
\hline $\begin{array}{l}\text { Meerwaldt } \\
\text { (2005) [34] }\end{array}$ & $\begin{array}{l}33 \mathrm{~T} 2 \mathrm{DM} \text { and } 13 \\
\text { T1DM/21 controls }\end{array}$ & Heart rate variability & Positive association \\
\hline $\begin{array}{l}\text { Orchard } \\
(2013)[35]\end{array}$ & 1185 T1DM & Heart rate variability & $\begin{array}{l}\text { Positive association before adjustment for mean } \mathrm{HbA}_{1 c} \text { over time; } \\
\text { insignificant association after adjustment }\end{array}$ \\
\hline $\begin{array}{l}\text { Conway } \\
\text { (2011) [42] }\end{array}$ & $111 \mathrm{T1DM}$ & $\begin{array}{l}\text { Electrocardiographic abnormal heart } \\
\text { rate response to deep breathing }\end{array}$ & $\begin{array}{l}\text { Multivariate analysis (adjustment for age and updated mean, 18-year } \\
\text { average, } \mathrm{HbA}_{1 \mathrm{c}} \text { ): positive association }\end{array}$ \\
\hline
\end{tabular}


Table 3 Key findings of the studies assessing the association between skin AGEs and DPN

1. Accumulation of skin AGEs is unanimously associated with DPN [36$38]$ and with diabetic foot ulceration $[40,41]$

2. Increasing SAF levels predict the development of impendent DPN $[22,31,38]$

3. Evidence supports that the increase in skin AGEs may precede smallfibre sudomotor dysfunction [31] and altered vibration perception threshold $[40,41]$

4. Important limitations of published studies include: populations with different diabetes types; application of varying definitions for DPN diagnosis; divergent implementation of sAF cut-off values

5. Future studies are eagerly anticipated to clarify important issues, namely improvement in DN as a result of AGEs screening and the costeffectiveness of the latter

AGEs advanced glycation end products, DPN diabetic peripheral neuropathy, SAF skin autofluorescence

Clarification of all these issues will help our decisions on the implementation of AGEs measurement in everyday reality, with the aim to improve outcomes of DPN, a still valid strategic priority [46-49].

One may be tempted to even extend these thoughts to the complications of $\mathrm{DN}$, primarily diabetic foot ulcers (DFUs) [1, 2, 48]. Treatment of the latter is still based on revascularisation (if needed), debridement, infection control and off-loading, while other measures are used secondarily [50]. This therapeutic approach has not changed, because no other intervention has demonstrated superiority [50]. There is also some progress in utilisation of screening tools to predict future development of DFUs, and, very recently, the indicator test for sudomotor function Neuropad has emerged as useful in this prediction [51]. One step earlier, timely identification of subjects at high risk of developing DN would also contribute to the identification of subjects at high risk of DFUs [50, 51]. Accordingly, skin AGEs measurement might prove useful as a surrogate marker of DFUs risk and, thus, contribute to meticulous treatment and education of subjects with this risk. This possibility notwithstanding, the potential utility of skin AGEs needs to be shown in practice.

\section{Conclusions}

Skin autofluorescence represents a non-invasive, inexpensive, highly reproducible method of measuring AGEs. Increased skin AGEs have been linked with microvascular complications of DM. In retinopathy, some correlation has been shown between AGEs and progression of this complication. Additionally, skin AGEs are being increasingly appreciated as predictors of nephropathy and DN. They appear to become increased before the impairment of nerve conduction parameters, onset of symptoms or increase in vibration perception threshold.

\section{Abbreviations \\ ACR: Albumin-to-creatinine ratio; AGEs: Advanced glycation endproducts: BMI: Body mass index; CML: Carboxymethyl-lysine; Cr: Creatinine; DM: Diabetes mellitus; DN: Diabetic neuropathy; DPN: Diabetic peripheral neuropathy; eGFR: estimated glomerular filtration rate; ELISA: Enzyme-linked immunosorbent assay; $\mathrm{HbA}_{1}$ : Glycated haemoglobin; HDL: High density lipoprotein; HPLC: High-performance liquid chromatography; LDL: Low density lipoprotein; NADPH: Nicotinamide adenine dinucleotide phosphate; RAGE: Receptor of advanced glycation end products; ROS: Reactive oxygen species; SAF: Skin autofluorescence; T1DM: Type 1 diabetes mellitus; T2DM: Type 2 diabetes mellitus}

\section{Acknowledgements}

None.

Authors' contributions

NP conceived the idea, edited and finalised the manuscript. SP and KP wrote the first draft of the manuscript. All authors contributed to and approved the final manuscript.

\section{Funding}

None.

\section{Availability of data and materials}

Not applicable, because this is a narrative review without original research data.

\section{Ethics approval and consent to participate}

Not applicable, because this is a narrative review without original research data.

\section{Consent for publication}

Not applicable, because this is a narrative review without original research data, without patient inclusion and without patient information.

\section{Competing interests}

This review was written independently. The authors did not receive financial or professional help with the preparation of the manuscript. NP has been an advisory board member of TrigoCare International, Abbott, AstraZeneca, Elpen, MSD, Novartis, Novo Nordisk, Sanofi-Aventis and Takeda; has participated in sponsored studies by Eli Lilly, MSD, Novo Nordisk, Novartis and Sanofi-Aventis; received honoraria as a speaker for AstraZeneca, Boehringer Ingelheim, Eli Lilly, Elpen, Galenica, MSD, Mylan, Novartis, Novo Nordisk, Pfizer, Sanofi-Aventis, Takeda and Vianex; and attended conferences sponsored by TrigoCare International, AstraZeneca, Boehringer Ingelheim, Eli Lilly, Novartis, Novo Nordisk, Pfizer and Sanofi-Aventis. The other authors report no conflicts of interest.

Received: 6 May 2020 Accepted: 10 February 2021

Published online: 23 February 2021

References

1. Pop-Busui R, Boulton AJ, Feldman EL, Bril V, Freeman R, Malik RA, et al. Diabetic neuropathy: a position statement by the American Diabetes Association. Diabetes Care. 2017:40:136-54.

2. Pafili K, Papanas N, Ziegler D. Neuropathy in diabetes: "one cannot begin it too soon." Angiology 2018;69:752-754.

3. Papanas N, Vinik Al, Ziegler D. Neuropathy in prediabetes: does the clock start ticking early? Nat Rev Endocrinol. 2011;7:682-90.

4. Bönhof GJ, Herder C, Strom A, Papanas N, Roden M, Ziegler D. Emerging biomarkers, tools, and treatments for diabetic polyneuropathy. Endocr Rev. 2019;40:153-92.

5. Stirban A, Heinemann L. Skin autofluorescence - a non-invasive measurement for assessing cardiovascular risk and risk of diabetes. Eur Endocrinol. 2014;10:106-10.

6. Snelson M, Coughlan MT. Dietary advanced glycation end products: digestion, metabolism and modulation of gut microbial ecology. Nutrients. 2019;11:2. 
7. Chen XUE, Pyzik R, Yong A, Striker GE. AGE's in foods and practical ways to reduce them. J Am Diet Assoc. 2013;110:911-6.

8. Bos DC, de Ranitz-Greven WL, de Valk HW. Advanced glycation end products, measured as skin autofluorescence and diabetes complications: a systematic review. Diabetes Technol Ther. 2011;13:773-9.

9. Van Waateringe RP, Slagter SN, Van Beek AP, van der Klauw MM, van VlietOstaptchouk JV, Graaff R, et al. Skin autofluorescence, a non-invasive biomarker for advanced glycation end products, is associated with the metabolic syndrome and its individual components. Diabetol Metab Syndr. 2017;9:42.

10. Yamagishi S, Matsui T, Nakamura K. Possible involvement of tobaccoderived advanced glycation end products (AGEs) in an increased risk for developing cancers and cardiovascular disease in former smokers. Med Hypotheses. 2008;71:259-61.

11. Isami F, West BJ, Nakajima S, Yamagishi SI. Association of advanced glycation end products, evaluated by skin autofluorescence, with lifestyle habits in a general Japanese population. J Int Med Res. 2018;46:1043-51.

12. Gatopoulou A, Papanas N, Maltezos E. Diabetic gastrointestinal autonomic neuropathy: current status and new achievements for everyday clinical practice. Eur J Intern Med. 2012;23:499-505.

13. Papanas $\mathrm{N}$, Ziegler D. Risk factors and comorbidities in diabetic neuropathy: an update 2015. Rev Diabet Stud. 2015;12:48-62.

14. Vlassara H, Striker GE. Advanced glycation endproducts in diabetes and diabetic complications. Endocrinol Metab Clin N Am. 2013;42:697-719.

15. Selvarajah D, Kar D, Khunti K, Davies MJ, Scott AR, Walker J, et al. Diabetic peripheral neuropathy: advances in diagnosis and strategies for screening and early intervention. Lancet Diabetes Endocrinol. 2019;7:938-48.

16. Pafili K, Trypsianis G, Papazoglou D, Maltezos E, Papanas N. Correlation of cardiac autonomic neuropathy with small and large peripheral nerve function in type 2 diabetes mellitus. Diabetes Res Clin Pract. 2019;156:107844.

17. Papanas N, Pafili K, Demetriou M, Chatzikosma G, Papachristou S, Papazoglou D. Automated measurement of sural nerve conduction is a useful screening tool for peripheral neuropathy in type 1 diabetes mellitus. Rev Diabet Stud. 2019;15:58-9.

18. Papanas N. Diabetic neuropathy collection: progress in diagnosis and screening. Diabetes Ther. 2020;11:761-4.

19. Ardeleanu V, Toma A, Pafili K, Papanas N, Motofei I, Diaconu CC, et al. Current pharmacological treatment of painful diabetic neuropathy: a narrative review. Medicina. 2020;56(1)

20. Smit AJ, Gerrits EG. Skin autofluorescence as a measure of advanced glycation endproduct deposition: a novel risk marker in chronic kidney disease. Curr Opin Nephrol Hypertens. 2010;19:527-33.

21. Fokkens BT, Smit AJ. Skin fluorescence as a clinical tool for non-invasive assessment of advanced glycation and long-term complications of diabetes. Glycoconj J. 2016;33:527-35.

22. Gerrits EG, Lutgers HL, Kleefstra N, Graaff R, Groenier KH, Smit AJ, et al. Skin autofluorescence: a tool to identify type 2 diabetic patients at risk for developing microvascular complications. Diabetes Care. 2008;31:517-21.

23. Chabroux S, Canouï-Poitrine F, Reffet S, Mills-Joncour G, Morelon E, Colin C, et al. Advanced glycation end products assessed by skin autofluorescence in type 1 diabetics are associated with nephropathy, but not retinopathy. Diabetes Metab. 2010;36:152-7.

24. Sugisawa E, Miura J, Iwamoto Y, Uchigata Y. Skin autofluorescence reflects integration of past long-term glycemic control in patients with type 1 diabetes. Diabetes Care. 2013;36:2339-45.

25. Yoshioka K. Skin autofluorescence is a noninvasive surrogate marker for diabetic microvascular complications and carotid intima-media thickness in Japanese patients with type 2 diabetes: a cross-sectional study. Diabetes Ther. 2018;9:75-85

26. Bentata R, Cougnard-Grégoire A, Delyfer MN, Delcourt C, Blanco L, Pupier E, et al. Skin autofluorescence, renal insufficiency and retinopathy in patients with type 2 diabetes. J Diabetes Complicat. 2017;31:619-23.

27. Tanaka K, Tani Y, Asai J, Nemoto F, Kusano Y, Suzuki H, et al. Skin autofluorescence is associated with severity of vascular complications in Japanese patients with type 2 diabetes. Diabet Med. 2012;29:492-500.

28. Yasuda M, Shimura M, Kunikata H, Kanazawa H, Yasuda K, Tanaka Y, et al. Relationship of skin autofluorescence to severity of retinopathy in type 2 diabetes. Curr Eye Res. 2015;40:338-45.

29. Hirano T, lesato $Y$, Toriyama Y, Imai A, Chiba D, Murata T. Correlation between diabetic retinopathy severity and elevated skin autofluorescence as a marker of advanced glycation end-product accumulation in type 2 diabetic patients. J Diabetes Complicat. 2014;28:729-34.
30. Noordzij MJ, Mulder DJ, Oomen PH, Brouwer T, Jager J, Castro Cabezas M, et al. Skin autofluorescence and risk of micro- and macrovascular complications in patients with type 2 diabetes mellitus-a multi-Centre study. Diabet Med. 2012;29:1556-61.

31. Rajaobelina K, Farges B, Nov S, Maury E, Cephise-Velayoudom FL, Gin H, et al. Skin autofluorescence and peripheral neuropathy four years later in type 1 diabetes. Diabetes Metab Res Rev. 2017;33:e2832.

32. Nagaraj RH, Oya-ito T, Bhat M, Liu B. Dicarbonyl stress and apoptosis of vascular cells: prevention by aB-Crystallin. Ann N Y Acad Sci. 2005;1043:158-65.

33. Ejaz S, Chekarova I, Ejaz A, Sohail A, Lim CW. Importance of pericytes and mechanisms of pericyte loss during diabetes retinopathy. Diabetes Obes Metab. 2008;10:53-63.

34. Meerwaldt R, Links TP, Graaff R, Hoogenberg K, Lefrandt JD, Baynes JW et al. Increased accumulation of skin advanced glycation end-products precedes and correlates with clinical manifestation of diabetic neuropathy. Diabetologia. 2005:48:1637-44.

35. Orchard TJ, Lyons TJ, Cleary PA, Braffett BH, Maynard J, Cowie C, et al. The association of skin intrinsic fluorescence with type 1 diabetes complications in the DCCT/EDIC study. Diabetes Care. 2013;36:3146-53.

36. Osawa S, Katakami N, Sato I, Ninomiya H, Omori K, Yamamoto Y, et al. Skin autofluorescence is associated with vascular complications in patients with type 2 diabetes. J Diabetes Complicat. 2018;32:839-44.

37. Wan L, Qin G, Yan W, Sun T. Skin autofluorescence is associated with diabetic peripheral neuropathy in chinese patients with type 2 diabetes: a cross-sectional study. Genet Test Mol Biomarkers. 2019;23:387-92.

38. Stirban AO, Bondor Cl, Florea B, Veresiu IA, Gavan NA. Skin autofluorescence: correlation with measures of diabetic sensorimotor neuropathy. J Diabetes Complicat. 2018;32:851-6.

39. Bierhaus A, Fleming T, Stoyanov S, Leffler A, Babes A, Neacsu C, et al. Methylglyoxal modification of Nav1.8 facilitates nociceptive neuron firing and causes hyperalgesia in diabetic neuropathy. Nat Med. 2012;18:926-33.

40. Hu H, Han CM, Hu XL, Ye WL, Huang WJ, Smit AJ. Elevated skin autofluorescence is strongly associated with foot ulcers in patients with diabetes: a cross-sectional, observational study of Chinese subjects. J Zhejiang Univ Sci B. 2012;13:372-7.

41. Vouillarmet J, Maucort-Boulch D, Michon P, Thivolet C. Advanced glycation end products assessed by skin autofluorescence: a new marker of diabetic foot ulceration. Diabetes Technol Ther. 2013;15:601-5.

42. Conway BN, Aroda VR, Maynard JD, Matter N, Fernandez S, Ratner RE, et al. Skin intrinsic fluorescence correlates with autonomic and distal symmetrical polyneuropathy in individuals with type 1 diabetes. Diabetes Care. 2011;34:1000-5.

43. Stirban A, Gawlowski T, Roden M. Vascular effects of advanced glycation endproducts: clinical effects and molecular mechanisms. Mol Metab. 2014;3: 2212-8778.

44. Stirban A. Noninvasive skin fluorescence spectroscopy for diabetes screening. J Diabetes Sci Technol. 2013;7:1001-4.

45. Stirban A. Measurement of lens autofluorescence for diabetes screening. J Diabetes Sci Technol. 2014;8:50-3.

46. Ziegler D, Papanas N, Schnell O, Nguyen BDT, Nguyen KT, Kulkantrakorn K, et al. Current concepts in the management of diabetic polyneuropathy. Diabetes Invest. 2020. https://doi.org/10.1111/jdi.13401 Online ahead of print

47. Shiferaw WS, Akalu TY, Work Y, Aynalem YA. Prevalence of diabetic peripheral neuropathy in Africa: a systematic review and meta-analysis. BMC Endocr Disord. 2020;20:49.

48. Fernando ME, Crowther RG, Cunningham M, Lazzarini PA, Sangla KS, Golledge J. Lower limb biomechanical characteristics of patients with neuropathic diabetic foot ulcers: the diabetes foot ulcer study protocol. BMC Endocr Disord. 2015;15:59.

49. Lee CM, Chang CC, Pan MY, Chang CF, Chen MY. Insufficient early detection of peripheral neurovasculopathy and associated factors in rural diabetes residents of Taiwan: a cross-sectional study. BMC Endocr Disord. 2014;14:89.

50. Boulton AJM. The 2017 Banting memorial lecture. The diabetic lower limb - a forty year journey: from clinical observation to clinical science. Diabet Med. 2019:36:1539-49.

51. Panagoulias GS, Eleftheriadou I, Papanas N, Manes C, Kamenov Z, Tesic D, et al. Dryness of foot skin assessed by the visual indicator test and risk of diabetic foot ulceration: a prospective observational study. Front Endocrinol. 2020;11:625.

\section{Publisher's Note}

Springer Nature remains neutral with regard to jurisdictional claims in published maps and institutional affiliations. 